\title{
School Attendance Registers for the Syndromic Surveillance of Infectious Intestinal Disease in UK Children: Protocol for a Retrospective Analysis
}

Anna L Donaldson ${ }^{1,2,3}$, MBBCHIR; John P Harris ${ }^{1,2}$, PhD; Roberto Vivancos ${ }^{1,3}$, LMS, MD; Daniel Hungerford ${ }^{1,3,4}$, $\mathrm{PhD}$; Ian Hall ${ }^{1,5}$, PhD; Sarah J O'Brien ${ }^{1,2}$, MBBS

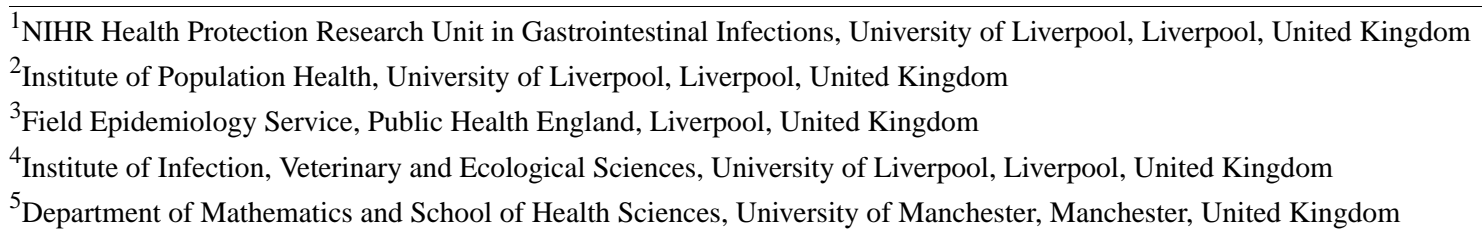

\section{Corresponding Author:}

Anna L Donaldson, MBBCHIR

NIHR Health Protection Research Unit in Gastrointestinal Infections

University of Liverpool

2nd Floor, Block F, Waterhouse Buildings

1-5 Brownlow Street

Liverpool, L69 3GL

United Kingdom

Phone: 441517958347

Email: A.Donaldson2@liverpool.ac.uk

\section{Abstract}

Background: Infectious intestinal disease (IID) is common, and children are more likely than adults both to have IID and to transmit infection onto others. Before the introduction of the vaccine, rotavirus was the leading cause of severe childhood diarrhea, with norovirus and Campylobacter predominate pathogens. Public health surveillance of IID is primarily based on health care data, and as such, illness that is managed within the community will often go undetected. School attendance registers offer a novel data set that has the potential to identify community cases and outbreaks of IID that would otherwise be missed by current health surveillance systems. Although studies have explored the role of school attendance registers in the monitoring of influenza among children, no studies have been identified that consider this approach in the surveillance of IID.

Objective: The aim of this study is to explore the role and utility of school attendance registers in the detection and surveillance of IID in children. The secondary aims are to estimate the burden of IID on school absenteeism and to assess the impact of the rotavirus vaccine on illness absence among school-aged children.

Methods: This study is a retrospective analysis of school attendance registers to investigate whether school absences due to illness can be used to capture seasonal trends and outbreaks of infectious intestinal disease among school-aged children. School absences in Merseyside, United Kingdom will be compared and combined with routine health surveillance data from primary care, laboratories, and telehealth services. These data will be used to model spatial and temporal variations in the incidence of IID and to apportion likely causes to changes in school absenteeism trends. This will be used to assess the potential utility of school attendance data in the surveillance of IID and to estimate the burden of IID absenteeism in schools. It will also inform an analysis of the impact of the rotavirus vaccine on disease within this age group.

Results: This study has received ethical approval from the University of Liverpool Research Ethics Committee (reference number 1819). Use of general practice data has been approved for the evaluation of rotavirus vaccination in Merseyside by NHS Research Ethics Committee, South Central-Berkshire REC Reference 14/SC/1140.

Conclusions: This study is unique in considering whether school attendance registers could be used to enhance the surveillance of IID. Such data have multiple potential applications and could improve the identification of outbreaks within schools, allowing early intervention to reduce transmission both within and outside of school settings. These data have the potential to act as an 
early warning system, identifying infections circulating within the community before they enter health care settings. School attendance data could also inform the evaluation of vaccination programs, such as rotavirus and, in time, norovirus.

International Registered Report Identifier (IRRID)： DERR1-10.2196/30078

(JMIR Res Protoc 2022;11(1):e30078) doi: 10.2196/30078

\section{KEYWORDS}

syndromic surveillance; schools; children; absenteeism; infectious intestinal disease; diarrhea and vomiting; school attendance registers

\section{Introduction}

Infectious intestinal diseases (IIDs) are common in both highand low-income countries, causing an estimated 2 billion cases globally each year [1]. Norovirus is the leading cause of IID, with Campylobacter the most common bacterial cause [1-3]. In children, rotavirus has been a major cause of severe IID until the licensing of the vaccine in 2006 [4]. The high incidence of IID infection results in significant disease burden and economic costs due to work and school absenteeism, lost earnings, reduced workforce productivity, and increased health care use [5-7]. In the United Kingdom alone, IID has been estimated to result in one million additional general practice consultations each year [6], and norovirus, rotavirus, and Campylobacter combined cost the UK economy an estimated $£ 150$ million (US \$200 million) per annum [5]. Over $80 \%$ of total costs are borne by patients, driven by lost income and out-of-pocket expenses [5].

Children are disproportionately affected by IID, with those younger than 5 years accounting for $38 \%$ of foodborne cases globally [1]. Children are thought to be important transmitters of IID infection and experience prolonged symptoms and viral shedding, reduced immunity, and higher levels of infectiousness [8-12]. The majority of a child's close contacts are based at school and home $[13,14]$, and infections, especially viruses, can spread easily through these semienclosed environments [15]. This not only increases the risk of outbreaks within school settings but also provides a pathway through which infections can spread from schools into the wider community $[13,16,17]$. There is evidence that children may be the first affected by seasonal and pandemic disease [18-21], and hence, enhancing infectious disease surveillance in schools could not only improve the health of children but also provide advanced warning before infections start to circulate in the wider community.

Public health surveillance of IID is primarily based on health care data such as laboratory reports, statutory notifications, hospital admissions, primary care consultations, and calls to remote telehealth services $[22,23]$. The majority of IID cases, however, will be managed in the community, without involvement from health care services. As a result, current surveillance is likely to be substantially underestimating the impact of IID. Furthermore, there is an inherent bias in the surveillance of IID, as certain groups are more susceptible to complications and therefore more likely to present to health care, such as the very young, the comorbid, and older adults $[2,3,24,25]$. Laboratory testing policies can also be targeted toward detecting pathogens in these high-risk groups [26], further increasing the surveillance bias. Enhancing the surveillance of IID and improving detection of community cases of disease would provide important information on the epidemiology of these infections. Such data would be of value to support the evaluation of public health interventions, such as rotavirus vaccination and, in time, norovirus vaccination. As vaccinations can alter the epidemiology of infection [27], it is crucial we are able to accurately monitor the long-term impact and effectiveness of these interventions, not only on health care services but also on prevalence in the community.

School attendance registers offer a novel data set that could be used to identify community cases of IID that might not otherwise be detected. School absenteeism data have shown potential in the surveillance of both seasonal and pandemic influenza [28-35], but no studies have been identified that consider their role in monitoring IID. Although mild cases of diarrhea and vomiting will not necessitate contact with health care services, they are likely to still result in an absence from school for the duration of the illness and, in line with public health guidance, an additional 48 hours after symptoms have resolved [36]. This provides a routine data set that has the potential to capture illness from the day of onset.

This study aims to explore the role and utility of school attendance registers in the detection and surveillance of IID in children. The secondary aims are to estimate the burden of IID on school absenteeism and to assess the impact of the rotavirus vaccine on illness absence among school-aged children.

\section{Methods}

\section{Study Setting}

This study will take place in local government areas within Merseyside in the North West of England. Merseyside is a predominately urban, metropolitan county with a population of 1.38 million, over 240,000 of whom are school-aged children [37]. It comprises five local government areas, which range in size from 145,000 residents to over 450,000 residents [37]. For this study, the population of interest is children aged 4-16 years who are registered at a school within Merseyside.

\section{Study Design}

The study will be a retrospective analysis of school absenteeism data to investigate whether school attendance registers can be used to capture seasonal trends and outbreaks of IID among school-aged children. Although these data are routinely collected by local government for school attendance management [38], this is a novel application of this data set. In the United Kingdom, all absences due to illness are given a single code, which distinguishes them from absences due to other causes, including those to attend medical appointments. However, the 
nature of the illness is not reported. Routine health surveillance data from primary care, laboratories, and the NHS 111 telehealth service will be used to model spatial and temporal variations in the incidence of IID and to apportion likely cause to changes in school absenteeism trends. This will allow an assessment to be made of the potential value and lead time of school absenteeism data in the surveillance of IID and the overall burden of IID on illness absenteeism. The impact of the rotavirus vaccine, which was introduced in the United Kingdom in 2013, will also be explored. As none of the school-aged children included in this study will have received the rotavirus vaccine, this study will capture the impact of vaccinating infants on herd immunity and reducing illness absenteeism among older, unvaccinated children [27].

\section{Data Sources}

School absenteeism data is available at the individual school level. Attendance data for schools providing primary (4-11 years of age) and secondary (11-16 years of age) education, regardless of type of school, will be sought from the local government in Merseyside, with data broken down by school and year group. Total absences and absences due to illness will be requested. Details of the number of children in each school and year group will also be obtained to allow corresponding rates to be calculated.

Laboratory data reported to Public Health England (PHE) North West will be used to obtain organism-specific rates of IID within the different geographical areas. These data are routinely collected and reported to PHE from diagnostic and reference laboratories [39]. PHE also holds data from NHS 111, which is a telehealth service that operates across England [40]. Calls to NHS 111 (and its precursor, NHS Direct) for diarrhea or vomiting will be used to indicate probable cases of IID. NHS 111 and NHS Direct data are held securely by the PHE Real-time Syndromic Surveillance team and can be accessed with permission via PHE.

Primary care consultations for diarrhea or vomiting will be used as another measure of probable cases of IID. These data have recently been collected from clinical commissioning groups and general practices across Merseyside to inform an evaluation of the rotavirus vaccine [41]. Read codes were used to distinguish acute cases of IID from cases linked to chronic conditions or noninfective causes [41]. These data can be accessed from the University of Liverpool in an anonymized format as a secondary data set to further inform the evaluation of the rotavirus vaccine.

To facilitate the spatiotemporal modeling, numbers from each data set will be aggregated to weekly rates to enable a common timescale. The spatial measurement will depend upon the data source; for school absenteeism data, the postcode of the school will be used alongside the catchment area (where appropriate). Primary care consultation data has been mapped to lower super output areas (LSOAs), which represents a geographical area with between 1000 and 3000 residents [42]. Laboratory data contains full postcodes, but to protect the anonymity of patients, these will be reduced to LSOAs before the data is transferred to the research team for analysis. Telehealth data contains only the postcode district of patients [43], which is a larger geographical aggregation than LSOA, ensuring anonymity. Denominator populations will be derived from the Office of National Statistics midyear population estimates [42]. Comparison of derived population estimates will be made with the Health and Safety Laboratories National Population Database [44], and the most suitable denominator population will be used.

To allow the analysis to be conducted at the year-group level, the surveillance data will include details of the patient's age (year of birth) and their sex. All other personally identifiable information will be removed from the data before it is transferred to the research team. The outcomes of the analysis will be based on aggregated data.

\section{Study Period}

Data will be examined retrospectively from July 2007 to June 2016, capturing 9 IID seasons. Each season is considered to start in calendar week 27 and end in calendar week 26 of the following year.

\section{Population Sample}

This study will focus on three of the five local government areas within Merseyside to reflect the coverage of primary care data collected to inform an evaluation of the rotavirus vaccine [45]. The population sample was estimated using data from the Department for Education, which holds a record of all local government-registered schools [46]. Data were based on the 2017/2018 academic year, limited to schools providing primary and secondary education (ages 4-16 years).

The total number of schools across the three local government areas is 372, consisting of 299 primary schools and 103 secondary schools. Of these schools, 30 deliver both primary and secondary education. The total pupil population across all included schools is 140,164 . Assuming that each year one in four pupils are affected by IID [47], in each academic year, we estimate there would be approximately 35,000 cases of IID in schools within the study area. As data will be requested over a 9-year period, the total number of cases across the study period is estimated to be 315,000 .

\section{Case Definitions}

The case definitions used within each data set are outlined in Textbox 1. 
Textbox 1. Case definitions.

School attendance registers

- Absence with registration code "I" (illness, not medical or dental appointments)

NHS 111 calls

- $\quad$ Calls for vomiting

- $\quad$ Calls for diarrhea

General practice consultations (read codes in parenthesis)

- $\quad$ Diarrhea and vomiting (19G)

- Diarrhea symptom not otherwise specified (19F6)

- Viral gastroenteritis (A07y0)

- Diarrhea (19F2)

- Gastroenteritis-presumed infectious origin (A0812)

- Diarrhea of presumed infectious origin (A083)

- Infantile viral gastroenteritis (A07y1)

- Infectious gastroenteritis (A0803)

- $\quad$ Enteritis due to rotavirus (A0762)

- Infectious diarrhea (A082)

Laboratory detections

- Detection of bacterial, viral, or protozoal infectious intestinal disease organisms in a fecal specimen

\section{Recruitment and Consent}

Recruitment will be conducted at a local government level. Local government will be approached via their public health departments and invited to participate in this study. Consent for use of aggregated school attendance data will be sought from the local government, who carry the legal responsibility for the data and its use. As the data are aggregated and anonymized, consent will not be sought from individual schools or parents.

\section{Data Analysis}

A descriptive analysis will be undertaken of each data set to examine and describe the temporal trends and seasonality of illness absenteeism rates and of confirmed and probable cases of IID. The analysis will be stratified by age to capture varying rates of disease in different year groups. Rotavirus-specific incidence data will be obtained from laboratory reports. The mathematical and statistical analysis will include an organism-specific dynamic transmission model and a mixed effect regression analysis to apportion cause to the variations in absenteeism and to estimate organism-specific incidence rates. The complexity of dynamical models will be decided during the project based on the outputs of the descriptive analysis. Rotavirus modeling will include an interrupted time series analysis to explore changes in school absenteeism rates pre- and postintroduction of the vaccine. This will support an assessment of the impact of vaccination on disease transmission in the community. Other organisms that commonly cause IID in children will also be included in the analysis (eg, norovirus and Campylobacter) to test the ability of illness absenteeism data to accurately detect seasonal trends and outbreaks of disease. This will inform an assessment of the suitability of school attendance registers as a potential form of disease surveillance in the community and its role in the long-term monitoring of vaccine-preventable diseases.

\section{Results}

This study received ethical approval from the University of Liverpool Research Ethics Committee (reference number 1819). Use of general practice data has been approved for the evaluation of rotavirus vaccination in Merseyside by the NHS Research Ethics Committee, South Central-Berkshire REC Reference 14/SC/1140. Study findings will be submitted to open access peer-reviewed journals and presented at scientific conferences and meetings, including meetings with stakeholders.

\section{Discussion}

Current surveillance of IID is predominantly based on health care data, and therefore, illness that is managed within the community will often go undetected. This study is unique in considering whether school absenteeism data could be used to enhance the surveillance of IID. The findings could have several important applications. These data could support the improved identification of outbreaks in schools, allowing early intervention to reduce transmission both within and outside of the school setting. As children may be the first affected by seasonal illness, these data have the potential to act as an early warning system, identifying infections circulating within the community before they enter health care settings. Absenteeism data could also be used to inform the evaluation of vaccination 
programs, such as rotavirus and potentially, in time, norovirus. Similarly, these data could be used to monitor the impact of health improvement programs such as handwashing interventions.

However, there are some limitations that should be considered. The most pertinent is the low specificity of the case definition for illness absenteeism. As a single code is used for all causes of illness absenteeism, these data cannot distinguish between absences caused by IID and absences from other illnesses such as respiratory tract infections. Therefore, the burden of IID on absenteeism cannot be directly measured, and modeling of routine surveillance data is required to apportion likely cause to changes in absenteeism rates. A further consideration in this study is the spatial measure available within each data set; the NHS 111 telehealth service does not collect information below the level of postcode district and hence the statistical modeling, when including this data set, will be restricted to this geographical level. This limits the ability of this analysis to test whether school absenteeism data can detect localized outbreaks of IID within communities. However, this reflects a limitation within our current surveillance systems and one that school attendance data has the potential to rectify. Future work should consider the feasibility of collecting symptom-specific absence information from schools to enhance the specificity of the data and support the syndromic surveillance of a broader range of childhood infectious disease.

\section{Acknowledgments}

This research was funded by the National Institute for Health Research (NIHR) Health Protection Research Unit (HPRU) in Gastrointestinal Infections at University of Liverpool in partnership with Public Health England, in collaboration with University of East Anglia, University of Oxford, and the Quadram Institute (grant NIHR HPRU 2012-10038). DH is funded by an NIHR Post-doctoral Fellowship (PDF-2018-11-ST2-006). IH is supported by the UK Research and Innovation through the JUNIPER modeling consortium (grant MR/V038613/1). The views expressed are those of the authors and not necessarily those of the National Health Service, the NIHR, the Department of Health and Social Care, or Public Health England.

\section{Authors' Contributions}

ALD, JPH, RV, DH, and SJO all contributed to the study design. IH contributed to the statistical methods. ALD wrote the first draft of the manuscript. All authors read and approved the final manuscript.

\section{Conflicts of Interest}

DH report grants on the topic of rotavirus vaccines, outside of the submitted work, from GlaxoSmithKline Biologicals, Sanofi Pasteur, and Merck and Co (Kenilworth, NJ) after the closure of Sanofi Pasteur-MSD in December 2016. RV report grants on the topic of rotavirus vaccines, outside of the submitted work, from GlaxoSmithKline Biologicals. ALD, JPH, IH, and SJO have nothing to disclose.

\section{References}

1. Kirk MD, Pires SM, Black RE, Caipo M, Crump JA, Devleesschauwer B, et al. World Health Organization estimates of the global and regional disease burden of 22 foodborne bacterial, protozoal, and viral diseases, 2010: a data synthesis. PLoS Med 2015 Dec;12(12):e1001921 [FREE Full text] [doi: 10.1371/journal.pmed.1001921] [Medline: 26633831]

2. Allos BM. Campylobacter jejuni infections: update on emerging issues and trends. Clin Infect Dis 2001 Apr 15;32(8):1201-1206. [doi: 10.1086/319760] [Medline: 11283810 ]

3. Glass RI, Parashar UD, Estes MK. Norovirus gastroenteritis. N Engl J Med 2009 Oct 29;361(18):1776-1785 [FREE Full text] [doi: $\underline{10.1056 / N E J M r a 0804575}$ ] [Medline: $\underline{19864676}$ ]

4. Tate J, Burton A, Boschi-Pinto C, Steele A, Duque J, Parashar U. 2008 estimate of worldwide rotavirus-associated mortality in children younger than 5 years before the introduction of universal rotavirus vaccination programmes: a systematic review and meta-analysis. The Lancet Infectious Diseases 2012 Feb;12(2):136-141. [doi: 10.1016/s1473-3099(11)70253-5]

5. Tam CC, O'Brien SJ. Economic cost of campylobacter, norovirus and rotavirus disease in the United Kingdom. PLoS One 2016;11(2):e0138526 [FREE Full text] [doi: 10.1371/journal.pone.0138526] [Medline: 26828435]

6. Tam CC, Rodrigues LC, Viviani L, Dodds JP, Evans MR, Hunter PR, IID2 Study Executive Committee. Longitudinal study of infectious intestinal disease in the UK (IID2 study): incidence in the community and presenting to general practice. Gut 2012 Jan;61(1):69-77 [FREE Full text] [doi: 10.1136/gut.2011.238386] [Medline: 21708822]

7. Roberts JA, Cumberland P, Sockett PN, Wheeler J, Rodrigues LC, Sethi D, Infectious Intestinal Disease Study Executive. The study of infectious intestinal disease in England: socio-economic impact. Epidemiol Infect 2003 Feb;130(1):1-11. [doi: 10.1017/s0950268802007690] [Medline: $\underline{12613740]}$

8. Harris JP, Iturriza-Gomara M, Allen DJ, Kelly S, O'Brien SJ. Norovirus strain types found within the second infectious intestinal diseases (IID2) study an analysis of norovirus circulating in the community. BMC Infect Dis 2019 Jan 25;19(1):87 [FREE Full text] [doi: 10.1186/s12879-019-3706-z] [Medline: $\underline{\text { 30683063] }}$

9. Shah MP, Hall AJ. Norovirus illnesses in children and adolescents. Infect Dis Clin North Am 2018 Mar;32(1):103-118 [FREE Full text] [doi: 10.1016/j.idc.2017.11.004] [Medline: 29406972] 
10. Kirkwood CD, Streitberg R. Calicivirus shedding in children after recovery from diarrhoeal disease. J Clin Virol 2008 Nov;43(3):346-348. [doi: 10.1016/j.jcv.2008.08.001] [Medline: 18789755]

11. Simmons K, Gambhir M, Leon J, Lopman B. Duration of immunity to norovirus gastroenteritis. Emerg Infect Dis 2013 Aug;19(8):1260-1267. [doi: 10.3201/eid1908.130472] [Medline: 23876612]

12. Uhnoo I, Olding-Stenkvist E, Kreuger A. Clinical features of acute gastroenteritis associated with rotavirus, enteric adenoviruses, and bacteria. Arch Dis Child 1986 Aug;61(8):732-738 [FREE Full text] [doi: 10.1136/adc.61.8.732] [Medline: 3017237]

13. Béraud G, Kazmercziak S, Beutels P, Levy-Bruhl D, Lenne X, Mielcarek N, et al. The French connection: the first large population-based contact survey in France relevant for the spread of infectious diseases. PLoS One 2015;10(7):e0133203 [FREE Full text] [doi: 10.1371/journal.pone.0133203] [Medline: 26176549]

14. Glass LM, Glass RJ. Social contact networks for the spread of pandemic influenza in children and teenagers. BMC Public Health 2008 Feb 14;8:61 [FREE Full text] [doi: 10.1186/1471-2458-8-61] [Medline: 18275603]

15. Barker J, Stevens D, Bloomfield S. Spread and prevention of some common viral infections in community facilities and domestic homes. J Appl Microbiol 2001 Jul;91(1):7-21 [FREE Full text] [doi: 10.1046/j.1365-2672.2001.01364.x] [Medline: 11442709]

16. Cauchemez S, Bhattarai A, Marchbanks TL, Fagan RP, Ostroff S, Ferguson NM, Pennsylvania H1N1 working group. Role of social networks in shaping disease transmission during a community outbreak of 2009 H1N1 pandemic influenza. Proc Natl Acad Sci U S A 2011 Feb 15;108(7):2825-2830 [FREE Full text] [doi: 10.1073/pnas.1008895108] [Medline: 21282645]

17. Mossong J, Hens N, Jit M, Beutels P, Auranen K, Mikolajczyk R, et al. Social contacts and mixing patterns relevant to the spread of infectious diseases. PLoS Med 2008 Mar 25;5(3):e74 [FREE Full text] [doi: 10.1371/journal.pmed.0050074] [Medline: 18366252$]$

18. Bernard H, Höhne M, Niendorf S, Altmann D, Stark K. Epidemiology of norovirus gastroenteritis in Germany 2001-2009: eight seasons of routine surveillance. Epidemiol Infect 2014 Jan;142(1):63-74. [doi: 10.1017/S0950268813000435] [Medline: 23517686]

19. Cate TR. Clinical manifestations and consequences of influenza. Am J Med 1987 Jun 19;82(6A):15-19. [doi: 10.1016/0002-9343(87)90555-9] [Medline: $\underline{3591813]}$

20. Glezen WP, Couch RB. Interpandemic influenza in the Houston area, 1974-76. N Engl J Med 1978 Mar 16;298(11):587-592. [doi: 10.1056/NEJM197803162981103] [Medline: 628375]

21. Cox NJ, Subbarao K. Global epidemiology of influenza: past and present. Annu Rev Med 2000;51:407-421. [doi: 10.1146/annurev.med.51.1.407] [Medline: 10774473]

22. Elliot A, Morbey R, Hughes H, Harcourt S, Smith S, Loveridge P, et al. Syndromic surveillance - a public health legacy of the London 2012 Olympic and Paralympic Games. Public Health 2013 Aug;127(8):777-781. [doi: 10.1016/j.puhe.2013.05.007] [Medline: 23870845]

23. Wall PG, de Louvois J, Gilbert RJ, Rowe B. Food poisoning: notifications, laboratory reports, and outbreaks--where do the statistics come from and what do they mean? Commun Dis Rep CDR Rev 1996 Jun 21;6(7):R93-100. [Medline: $\underline{8680502]}$

24. Velázquez FR. Protective effects of natural rotavirus infection. Pediatr Infect Dis J 2009 Mar;28(3 Suppl):S54-S56. [doi: 10.1097/INF.0b013e3181967c03] [Medline: 19252424]

25. Kirk M, Veitch M, Hall G. Gastroenteritis and food-borne disease in elderly people living in long-term care. Clin Infect Dis 2010 Feb 01;50(3):397-404. [doi: 10.1086/649878] [Medline: 20047497]

26. Atchison C, Lopman B, Harris C, Tam C, Iturriza Gómara M, Gray J. Clinical laboratory practices for the detection of rotavirus in England and Wales: can surveillance based on routine laboratory testing data be used to evaluate the impact of vaccination? Euro Surveill 2009 May 21;14(20):19217 [FREE Full text] [doi: 10.2807/ese.14.20.19217-en] [Medline: 19460285]

27. Iturriza-Gómara M, Cunliffe N. Rotavirus vaccine: a welcome addition to the immunisation schedule in the UK. BMJ 2013 Apr 15;346:f2347. [doi: 10.1136/bmj.f2347] [Medline: 23587749]

28. Besculides M, Heffernan R, Mostashari F, Weiss D. Evaluation of school absenteeism data for early outbreak detection, New York City. BMC Public Health 2005 Oct 07;5:105 [FREE Full text] [doi: 10.1186/1471-2458-5-105] [Medline: 16212669]

29. Chu A, Savage R, Whelan M, Rosella LC, Crowcroft NS, Willison D, et al. Assessing the relative timeliness of Ontario's syndromic surveillance systems for early detection of the 2009 influenza H1N1 pandemic waves. Can J Public Health 2013 May 14;104(4):340-347 [FREE Full text] [doi: 10.17269/cjph.104.3721] [Medline: 24044464]

30. Kara EO, Elliot AJ, Bagnall H, Foord DGF, Pnaiser R, Osman H, et al. Absenteeism in schools during the 2009 influenza $\mathrm{A}(\mathrm{H} 1 \mathrm{~N} 1)$ pandemic: a useful tool for early detection of influenza activity in the community? Epidemiol Infect 2012 Jul;140(7):1328-1336. [doi: 10.1017/S0950268811002093] [Medline: 22014106]

31. Kightlinger L, Horan V. School illness absenteeism during 2009 influenza A (H1N1) pandemic--South Dakota, $2009-2010$. S D Med 2013 May;66(5):177, 179-177, 181. [Medline: 23798263]

32. Kom Mogto CA, De Serres G, Douville Fradet M, Lebel G, Toutant S, Gilca R, et al. School absenteeism as an adjunct surveillance indicator: experience during the second wave of the $2009 \mathrm{H} 1 \mathrm{~N} 1$ pandemic in Quebec, Canada. PLoS One 2012;7(3):e34084 [FREE Full text] [doi: 10.1371/journal.pone.0034084] [Medline: 22479531] 
33. Lenaway DD, Ambler A. Evaluation of a school-based influenza surveillance system. Public Health Rep 1995;110(3):333-337 [FREE Full text] [Medline: 7610226]

34. Ma T, Englund H, Bjelkmar P, Wallensten A, Hulth A. Syndromic surveillance of influenza activity in Sweden: an evaluation of three tools. Epidemiol Infect 2015 Aug;143(11):2390-2398 [FREE Full text] [doi: 10.1017/S0950268814003240] [Medline: 25471689]

35. Schmidt W, Pebody R, Mangtani P. School absence data for influenza surveillance: a pilot study in the United Kingdom. Euro Surveill 2010 Jan 21;15(3):19467 [FREE Full text] [Medline: 20122378]

36. Health protection in schools and other childcare facilities. Public Health England. 2017. URL: https://www.gov.uk/ government/publications/health-protection-in-schools-and-other-childcare-facilities [accessed 2021-09-01]

37. 2011 Census: population estimates by five-year age bands, and household estimates, for local authorities in the United Kingdom. Office for National Statistics. 2013. URL: https://tinyurl.com/2xu4jn4j [accessed 2021-09-01]

38. School attendance: guidance for maintained schools, academies, independent schools and local authorities. Department for Education. 2020. URL: https://assets.publishing.service.gov.uk/government/uploads/system/uploads/attachment_data/file/ 907535/School attendance guidance for 2020 to 2021 academic year.pdf [accessed 2021-09-01]

39. Laboratory reporting to Public Health England: a guide for diagnostic laboratories. Public Health England. 2020. URL: https://assets.publishing.service.gov.uk/government/uploads/system/uploads/attachment_data/file/926838/

PHE Laboratory reporting guidelines October-2020-v3.pdf [accessed 2021-09-01]

40. When to use NHS 111. National Health Service. URL: https://www.nhs.uk/using-the-nhs/nhs-services/ urgent-and-emergency-care/nhs-111/ [accessed 2021-09-01]

41. Hungerford D, Vivancos R, French N, Iturriza-Gomara M, Cunliffe N. Ecological assessment of the direct and indirect effects of routine rotavirus vaccination in Merseyside, UK using data from multiple health systems: a study protocol. BMJ Open 2014 Nov 25;4(11):e006161 [FREE Full text] [doi: 10.1136/bmjopen-2014-006161] [Medline: 25424995]

42. Lower layer Super Output Area population estimates (supporting information). Office for National Statistics. 2020. URL: https://www.ons.gov.uk/peoplepopulationandcommunity/populationandmigration/populationestimates/datasets/ lowersuperoutputareamidyearpopulationestimates [accessed 2021-09-01]

43. Postal geography. Office for National Statistics. 2016. URL: https://www.ons.gov.uk/methodology/geography/ukgeographies/ postalgeography [accessed 2021-09-01]

44. The National Population Database. HSE Solutions. URL: https://www.hsl.gov.uk/what-we-do/data-analytics/ national-population-database [accessed 2021-09-01]

45. Hungerford D, Vivancos R, Read JM, Iturriza-Gómara M, French N, Cunliffe NA. Rotavirus vaccine impact and socioeconomic deprivation: an interrupted time-series analysis of gastrointestinal disease outcomes across primary and secondary care in the UK. BMC Med 2018 Jan 29;16(1):10 [FREE Full text] [doi: 10.1186/s12916-017-0989-z] [Medline: 29375036]

46. Department for Education. GOV.UK. URL: https://www.gov.uk/government/organisations/department-for-education [accessed 2021-09-01]

47. Tam C, Viviani L, Adak B, Bolton E, Dodds J, Cowden J, et al. The Second Study of Infectious Intestinal Disease in the Community (IID2 Study). Food Standards Agency. 2012. URL: http://www.food.gov.uk/sites/default/files/media/document/ 711-1-1393 IID2 FINAL REPORT.pdf [accessed 2021-09-01]

\author{
Abbreviations \\ HPRU: Health Protection Research Unit \\ IID: infectious intestinal disease \\ LSOA: lower super output area \\ NIHR: National Institute for Health Research \\ PHE: Public Health England
}

Edited by G Eysenbach; submitted 30.04.21; peer-reviewed by T Koritala, S Doan; comments to author 19.08.21; revised version
received 01.09.21; accepted 03.09.21; published 20.01.22
Please cite as:
Donaldson AL, Harris JP, Vivancos R, Hungerford D, Hall I, O'Brien SJ
School Attendance Registers for the Syndromic Surveillance of Infectious Intestinal Disease in UK Children: Protocol for a Retrospective
Analysis
JMIR Res Protoc 2022;11(1):e30078
URL: https://www.researchprotocols.org/2022/1/e30078
doi: $10.2196 / 30078$
PMID:


(C)Anna L Donaldson, John P Harris, Roberto Vivancos, Daniel Hungerford, Ian Hall, Sarah J O'Brien. Originally published in JMIR Research Protocols (https://www.researchprotocols.org), 20.01.2022. This is an open-access article distributed under the terms of the Creative Commons Attribution License (https://creativecommons.org/licenses/by/4.0/), which permits unrestricted use, distribution, and reproduction in any medium, provided the original work, first published in JMIR Research Protocols, is properly cited. The complete bibliographic information, a link to the original publication on https://www.researchprotocols.org, as well as this copyright and license information must be included. 